\title{
Montgomery Identity and Ostrowski Type Inequalities for a new Quantum Integral
}

\author{
Muhammad Aamir $\mathrm{Ali}^{1}$, Hüseyin BUDAK${ }^{2}$, and Mujahid Abbas ${ }^{3}$ \\ ${ }^{1}$ Nanjing Normal University School of Mathematical Sciences \\ ${ }^{2}$ Düzce University \\ ${ }^{3}$ Government College University Lahore
}

June 6, 2020

\begin{abstract}
In this paper, quantum version of Montgomery identity by applying $\$ \mathrm{q}^{\wedge}\{\mathrm{b}\} \$$-integral is obtained. By employing the established identity, some new quantum Ostrowski type inequalities are proved. Several special cases of our main results are presented. It is also shown that the results presented in this paper generalize several other well known inequalities given in the existing literature on this subject.
\end{abstract}

\section{Hosted file}

M002062020.pdf available at https://authorea.com/users/330633/articles/457420-montgomeryidentity-and-ostrowski-type-inequalities-for-a-new-quantum-integral 